\title{
THE FERTILIZATION OF OUR NATIVE SPECIES OF CLITORIA AND CENTROSEMA.
}

BY WILLIAM TRELEASE.

VISITOR to the Southern States in the early summer will
notice among the most conspicuous flowers of dry, open wood-borders and fields, the two related leguminous species known to botanists as Clitoria mariana and Centrosema virginiana; the former a low vine, sometimes twining for a few feet up some supporting shrub; the latter a strong, slender twiner, not infrequently ascending to the height of ten or more feet. In accordance with its small size, the former has, as a rule, but one or two flowers expanded at a time, and they are of a pale purple, so that it is far outshone by its relative, whose entire length is often covered by bright purple flowers-not quite so large, to be sure, as those of Clitoria, but compensating for diminished size by increased number and depth of color-hence a shrub covered by this vine in full bloom is often an object of great beauty.

If we examine a flower of either species we find that its vexillum or standard ( $s$, Fig. I) is the lowest petal, while in most leguminous plants it is the uppermost when the flower is in the position which it naturally occupies on the plant; and this position allows it to serve in the species under consideration as an alighting place for insects.

An examination of the flower of Clitoria will show that the lateral borders of the horizontal standard are folded upwards to form a trough, this structure forcing insects to enter the flower on the median line and leading them directly beneath the keel $(k)$. The uniform pale-purple color of the rest of the corolla is deviated from in this trough by the production of special guiding marks, which combine with the curvature of the standard to lead all insects into the flower in a constant direction. These marks consist of a yellowish spot near the apex of the standard, which narrows into a line following the middle line of the petal. From the base of this line radiate dark-purple lines on each side, their widest divergence being just below the widest part of the yellow line. The wing petals $(w)$ are colherent with the keel at the point $p$, and beyond this point they diverge somewhat, thus aiding in a slight degree the upturned borders of the standard. The keel is split on its lower border, but when undisturbed the edges are 
closely applied to each other. The filaments $(f)$ are united, excepting on the side next the vexillum. Within the base of the filaments is a large nectar gland $(n)$, broken on the side next the standard, and slightly five-lobed on its free surface, suggesting its homology with a whorl of five stamens. Through the break on its lower side and the breaks in the tube formed by the filaments, the abundantly-secreted nectar flows into the basal part of the standard, and it is to this that the guiding marks of this petal lead. The pistil consists of an elongated, stalked ovary $(0)$ and a slender style terminated by an enlarged stigma $(s t)$, which usually protrudes slightly from the tip of the keel when the flower is expanded.

From its structure it may be predicted that this flower is designed to be fertilized by bees, but though I have often carefully watched dozens of plants growing together, for a long time, I have never seen a bee visit one of them, though I have sometimes noticed a swiftly-flying black bee (Melissodes nigra) flying nervously among the flowers, and I have no doubt that this species, at least, visits them for their honey. Once I saw a butterfly (Callidryas eubule) standing on the keel and having its proboscis inserted between the bases of the keel and the wing petals, thus reaching the nectar at the base of the standard. To show what would happen if a bee entered the flower, we may insert the end of a small pencil between the vexillum and the tip of the keel. First of all this comes in contact with the stigma, and this would take up any pollen on its upper surface. Differently from what occurs in the majority of leguminous flowers, the rigid keel and standard do not readily move apart by a wedging action between them, but as we insert the pencil a little farther it encounters the wings on either hand and forces these apart laterally. In doing this the sides of the keel are slightly pulled apart, owing to their union with the wings, and the pollen collected in the keel is allowed to fall upon the pencil. That this is what occurs in nature when a bee visits the flower, I think there can be little doubt; though a set of collecting hairs (Fig. IV, $h$ ) on the inner side of the style makes it appear probable that the keel is forced somewhat upward, so as to cause these to pump out a quantity of pollen. In Central Alabama, where these observations were made, a fair percentage of the flowers set fruit, but I am unable to say whether the plant is self-fertile or not. 
In Centrosema the standard is either horizontal or considerably inclined, being nearly vertical in some cases; it is more nearly flat than in Clitoria, and its lateral margins are usually more or less noticeably bent downward. Near its base, on the middle
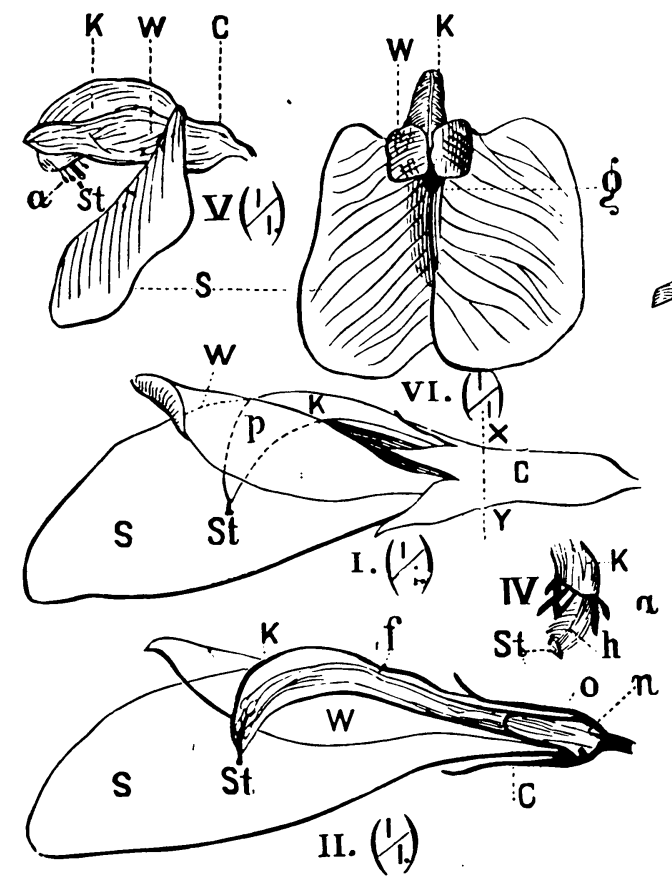
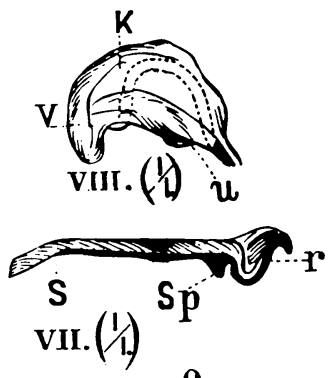

$\mathbf{0}$

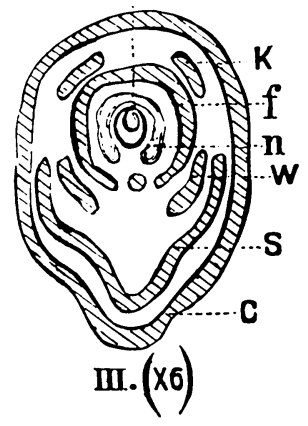

FIG. I-Flower of Clitoria mariana, with nearer half of vexillum removed, natural size.

FIG. II.-The same with the nearer wing and the nearer keel petal removed, as well as a part of the staminal tube and th. nearer half of the calyx.

FIG. III.-Cross section (diagrammatic) of Fig. I at $x y$.

Fig. IV.-Tip of the keel with the stamens and pistil unnaturally protruded, enlarged.

FIG. v.-Flower of Centrosema virginiana seen from the side, natural size. The keel is bent so as to expose the anthers and stigina.

Fig. vi.-The same from in front.

FIG. vir.-Vexillum of Fig. vi in longitudinal section, natural size.

FIG. virr.-Keel after removal of the wings and standard, natural size. The dotted line indicates the position of the stamen and pistil.

In all of the figures $a$ indicates the anthers; $c$, the calyx; $f$, the filaments; $g$, the guiding groove; $h$, the collecting hairs; $k$, the keel; $n$, the nectar-gland; $p$, the point of union of keel and wings; $r$, the nectar reservoir; $s$, the standard or vexillum; st, the stigma; $u$, part of the spring for retaining the keel in its normal position; $v$, the pouch for the stigma and anthers; $w$, the wings; $x y$, the point at which the section, Fig. III, is taken. 
line, this petal has a guiding groove $(g)$ of considerable depth, which connects with a slight cup $(r)$ at the very base, this cup serving as a receptacle for nectar. On its lower surface, just in front of this receptacle, the vexillum is provided with a solid spur ( $s p$, Fig. vil), which forms one character by which this genus is distinguished from Clitoria, but which seems to perform no function now. On the upper surface of the standard a white line, bordered on each side by fine lines of dark purple, runs from the basal guiding groove nearly to the apex of the petal, while others radiate from it on either hand, following the general direction of the veins of the standard. These marks, like those of the species last discussed, serve as guides to the nectar, which is poured into its receptacle, from a vaguely nine to ten-lobed annular gland, through the split in the staminal tube. The wings are coherent with the keel, are laterally inflated, and are so arranged as to prevent anything larger than the proboscis of a butterfly from reaching the nectar of the flower excepting by way of the guiding groove. The keel petals are grown together along both edges with the exception of a small space at their base and another at their apex. On the border next the vexillum, at about one-third the distance from its base to its apex, each keel-petal bulges outward to form an egg-shaped, thin-walled protuberance (Fig. viII, u), the two being approximated on the median line. Half way between this and the tip, another common inflation $(v)$ forms a closed pouch in which the stigma and anthers commonly lie, the style and stamens being strongly curved.

In reaching its head under the keel for the purpose of protruding its tongue into the nectar receptacle, through the guiding groove, a bee encounters the first-mentioned protrusion, which, with the inflated sides of the keel and the wings, acts as a spring, keeping the keel in its normal position, with the stigma and anthers concealed within it, in their pouch. But when this protruding pouch is pressed from below it bends the keel on its back and forces it slightly backward at its base, so that the stigma and anthers-which move but little-are protruded from the split apex of the keel and come in contact with the back of the bee. After the pressure is removed the elasticity of the parts returns them to their former position.

In spite of the guiding marks some insects fail to find the nectar. For example, one day in August an ichneumon-fly was seen 
to try anxiously to find access to the honey of several flowers, but in every case it tried to enter at the side of the wings, and always failed. One large butterfly was seen to insert its proboscis at the side of the wings, and as it remained quietly standing for some time it probably obtained nectar. Several small butterflies alighted on the vexillum and ran their proboscides down the guiding groove, but necessarily failed to fertilize the flowers as they exerted no pressure on the keel. Many humble bees were seen to enter the flowers. Catching their anterior tarsi on the sides of the standard, they pulled themselves between this and the keel by sheer force, and then relaxing their hold, they protruded their tongues and feasted upon the nectar. In every case they caused the stigma and anthers to be exserted, and these always came in contact with their backs. Where flowers had been visited many times by these bees the sides of the vexillum, and especially near its base, were greatly scratched, and in some cases cut through by their sharp tarsal claws. When the bee left the flower the keel invariably returned to its former position so as to enclose the organs of fertilization. Hive bees were also seen to visit flowers of this species several times, and they acted precisely as the humble bees did, and with a similar result.

Quite a number of flowers were seen with large perforations (Fig. vili) through both wing and keel, just back of the position commonly occupied by the anthers and stigma. As these did not allow access to the nectar, but did expose the pollen, I am inclined to think that they were made by some pollencollecting insect-probably humble bees-though I was unable to see the openings made or used by any insect. In Alabama, where these observations were made, the flowers of this plant are largely fertile, but it was not determined whether they are selffertile or not.

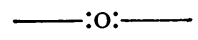

\section{RECENT LITERATURE.}

Clark's Anatomy and Physiology of the Lucernaria. ${ }^{1}$ American zoölogical science has, from the beginning, been especially lacking in histological investigations. The lamented author of the beautiful memoir before us, did far more than any one

${ }^{1}$ Lucernaria and their Allies. A memoir on the anatomy and physiology of Haliclystus auricula and other Lucernarians, with a discussion of their relations to other Acalephæ, to Beroirs and Polypi. By Henry James (inark, B.S., A.B. Smithsonian Contributions to Knowlerlge. Washington, September, 1878. 4to, pp. I30, I I plates. 